\title{
Mitochondrial calcium uniporter protein MCU is involved in oxidative stress-induced cell death
}

\author{
Yajin Liao ${ }^{1,2}$, Yumin Hao ${ }^{1}$, Hong Chen ${ }^{1}$, Qing $\mathrm{He}^{1,2}$, Zengqiang Yuan ${ }^{1 凶}$, Jinbo Cheng ${ }^{1 凶}$ \\ ${ }^{1}$ State Key Laboratory of Brain and Cognitive Sciences, Institute of Biophysics, Chinese Academy of Sciences, \\ Beijing 100101, China \\ ${ }^{2}$ College of Life Sciences, University of Chinese Academy of Sciences, Beijing 100049, China \\ $\bowtie$ Correspondence: zqyuan@ibp.ac.cn (Z. Yuan), cheng_jinbo@126.com (J. Cheng) \\ Received December 30, 2014 Accepted February 3, 2015
}

\begin{abstract}
Mitochondrial calcium uniporter (MCU) is a conserved $\mathrm{Ca}^{2+}$ transporter at mitochondrial in eukaryotic cells. However, the role of MCU protein in oxidative stressinduced cell death remains unclear. Here, we showed that ectopically expressed MCU is mitochondrial localized in both HeLa and primary cerebellar granule neurons (CGNs). Knockdown of endogenous MCU decreases mitochondrial $\mathrm{Ca}^{2+}$ uptake following histamine stimulation and attenuates cell death induced by oxidative stress in both HeLa cells and CGNs. We also found MCU interacts with VDAC1 and mediates VDAC1 overexpression-induced cell death in CGNs. This finding demonstrates that MCU-VDAC1 complex regulates mitochondrial $\mathrm{Ca}^{2+}$ uptake and oxidative stress-induced apoptosis, which might represent therapeutic targets for oxidative stress related diseases.
\end{abstract}

KEYWORDS MCU, VDAC1, oxidative stress, calcium uptake, cell death

\section{INTRODUCTION}

As the major source of ATP, mitochondrion plays an essential role in cellular physiology and metabolism in eukaryotic cells. On the one hand, low mitochondrial $\mathrm{Ca}^{2+}$ concentration fails to effectively activate pyruvate dehydrogenase as to produce enough ATP (Robb-Gaspers et al., 1998); on the other hand, overloaded mitochondrial $\mathrm{Ca}^{2+}$ reduces mitochondrial membrane potential $(\Delta \psi)$ and triggers cell death. Therefore, mitochondrial $\mathrm{Ca}^{2+}$ homeostasis is essential for physiological function and survival of the cells.
Some proteins involved in mitochondrial $\mathrm{Ca}^{2+}$ uptake have been discovered in recent years. VDAC (voltage-dependent anion channel) is the first identified $\mathrm{Ca}^{2+}$ transport channel, which locates in the outer membrane of mitochondria (OMM) and highly permeable to $\mathrm{Ca}^{2+}$ (Xu et al., 1999). VDAC1 will lose its $\mathrm{Ca}^{2+}$ transport capacity when the $\mathrm{Ca}^{2+}$ binding sites are blocked by Ruthenium Red (RuR) (Gincel et al., 2001). MCU is another identified $\mathrm{Ca}^{2+}$ uniporter protein, which is localized in the inner membrane of mitochondrion (IMM) (Baughman et al., 2011). Numbers of proteins have been shown to regulate the activity of $\mathrm{MCU}$, such as essential mitochondrial calcium uptake1/2 (MICU1/2), MCU regulator (EMRE), MCUb and MCU regulator 1 (MCUR1) (Ahuja and Muallem, 2014; Alam et al., 2012; Mallilankaraman et al., 2012a; Mallilankaraman et al., 2012b; Raffaello et al., 2013; Sancak et al., 2013). When cells undergo severe damage, mitochondrial permeability transition pore (PTP) will open and release pro-apoptotic factors, especially cytochrome c, from mitochondria to the cytoplasm (Kinnally et al., 2011). Overexpression of VDAC1 renders cells sensitive to oxidative stress inducers, such as thapsigargin (TG) and arsenic trioxide (As2O3) (Ben-Hail and Shoshan-Barmatz, 2012; Shoshan-Barmatz et al., 2010; Shoshan-Barmatz et al., 2009). Ectopically expressed VDAC1 increases the concentration of $\mathrm{Ca}^{2+}$ in the inner-membrane space of mitochondrion, leading to mitochondrial $\mathrm{Ca}^{2+}$ overload and cytochrome c release (Brustovetsky et al., 2002; Madesh and Hajnoczky, 2001; Naranmandura et al., 2012; Rapizzi et al., 2002). Cytochrome $c$ interacts with Apaf1 and initiates activation of caspase-3 (Chu et al., 2001). As a subunit of the PTP, VDAC1 is involved in cytochrome $c$ release and apoptosis (Zheng et al., 2004). Whether MCU, the inner membrane $\mathrm{Ca}^{2+}$ uniporter, has the similar function as 
VDAC1 protein in neurons is poorly studied. In our study, we found that MCU plays an important role in oxidative stressinduced apoptosis. In addition, we showed that MCU interacts with VDAC1 and is involved in the VDAC1-mediated cell death in CGNs.

\section{RESULTS}

MCU regulates the mitochondrial $\mathrm{Ca}^{2+}$ uptake in primary CGNs

First, we found that overexpressed MCU was mainly localized in the mitochondria in HeLa cells and CGNs (Fig. 1A and 1B). To identify whether $\mathrm{MCU}$ functions as mitochondrial $\mathrm{Ca}^{2+}$ uniporter in HeLa cells, two shRNAs against MCU were designed. As shown in Fig. 2A, shRNA\#1 had a better knockdown efficiency compared with shRNA\#2. In order to monitor mitochondrial $\mathrm{Ca}^{2+}$ levels, we transfected cells with a mitochondrial targeted $\mathrm{Ca}^{2+}$ indicator, Mito-GCaMP3. Knockdown of MCU dramatically decreased histamine-induced mitochondrial $\mathrm{Ca}^{2+}$ level, which includes both the peak $\mathrm{Ca}^{2+}$ level and the recovery time to baseline (Fig. 2B-D). Furthermore,
Figure 2. MCU is required for mitochondrial calcium uniporter in HeLa cells and CGNs. (A) Two shRNA against MCU were designed to knockdown MCU in HeLa cells and the knockdown efficiency of each was detected by Western blot. (B) Knocking down MCU decreased mitochondrial $\mathrm{Ca}^{2+}$ uptake by assaying Mito-GCaMP3. Control or MCU knockdown HeLa cells were transfected with Mito-GCaMP3. GCaMP3 fluorescence was measured before and during exposure to histamine stimulation (100 $\mu \mathrm{mol} / \mathrm{L})$. (C) Representative traces $\mathrm{Ca}^{2+}$ response to histamine stimulation in control or MCU knockdown HeLa cells. (D) Graph shows quantification of peak $\mathrm{Ca}^{2+}$ intensities. (E) Representative traces of $\mathrm{Ca}^{2+}$ uptake in digitonin-permeabilized HeLa cells. The level of $\mathrm{Ca}^{2+}$ was indicated by the calcium Green-5N. (F) Graph shows relative $\mathrm{Ca}^{2+}$ uptake. (G) CGNs were transfected with shMCU or shvector together with Mito-GCaMP3. GCaMP3 fluorescence was measured before and after exposure to histamine $(100 \mu \mathrm{mol} / \mathrm{L})$. (H) Representative traces showing $\mathrm{Ca}^{2+}$ response after histamine stimulation over time in MCU wild type or knockdown cells were. (I) Graph shows quantification of peak $\mathrm{Ca}^{2+}$ intensities.
A

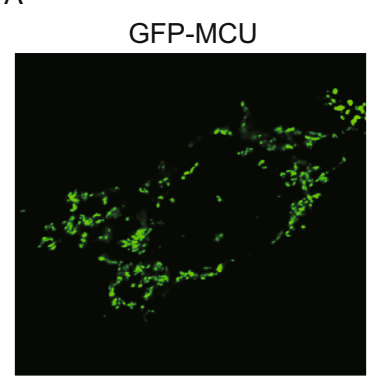

B

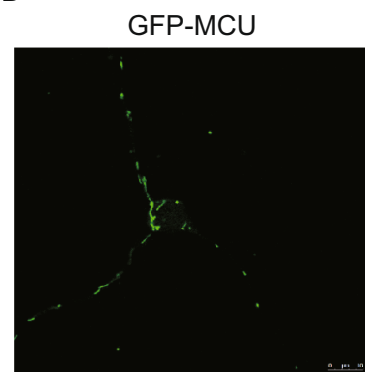

HeLa cells Tom20

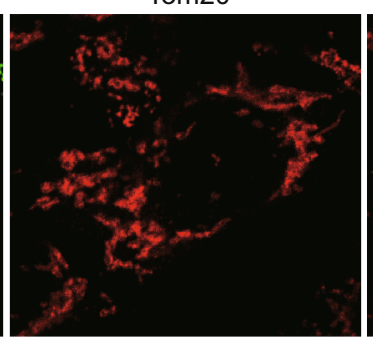

CGNs

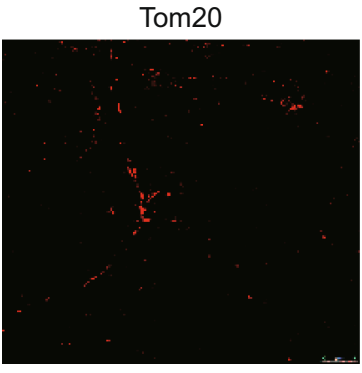

Merge

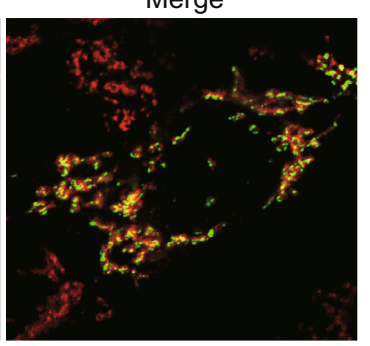

Merge

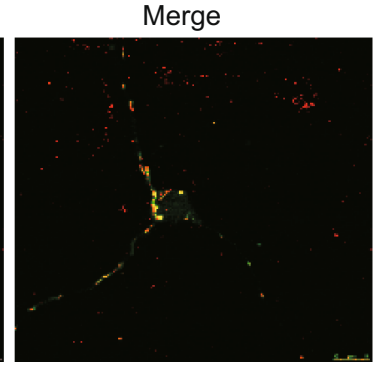

Figure 1. The sublocation of MCU in HeLa cells and CGN. (A) GFP-MCU (green) was tranfected into HeLa cells. Twenty-four hours post transfection, cells were fixed and stained with Tom20 (Red). (B) GFP-MCU (green) and mito-Red (red) were co-tranfected into CGNs. Twenty-four hours post transfection, cells were fixed and imaged by laser confocal microscope using a 40× objective lens. 
A

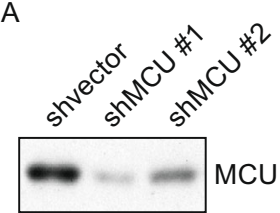

$2802 \mathrm{ERK} 1 / 2$

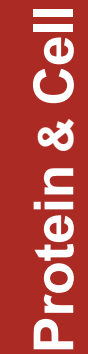

C
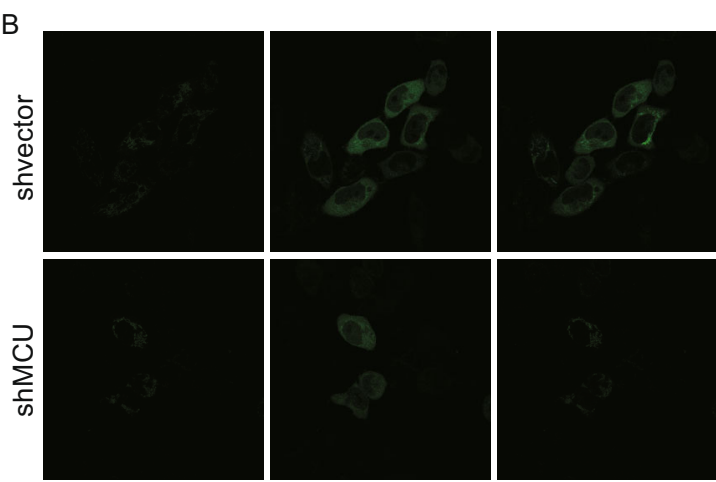

$20 \mathrm{~s}$
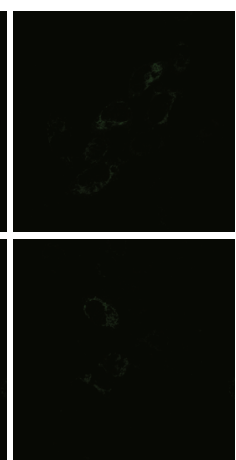

D

E
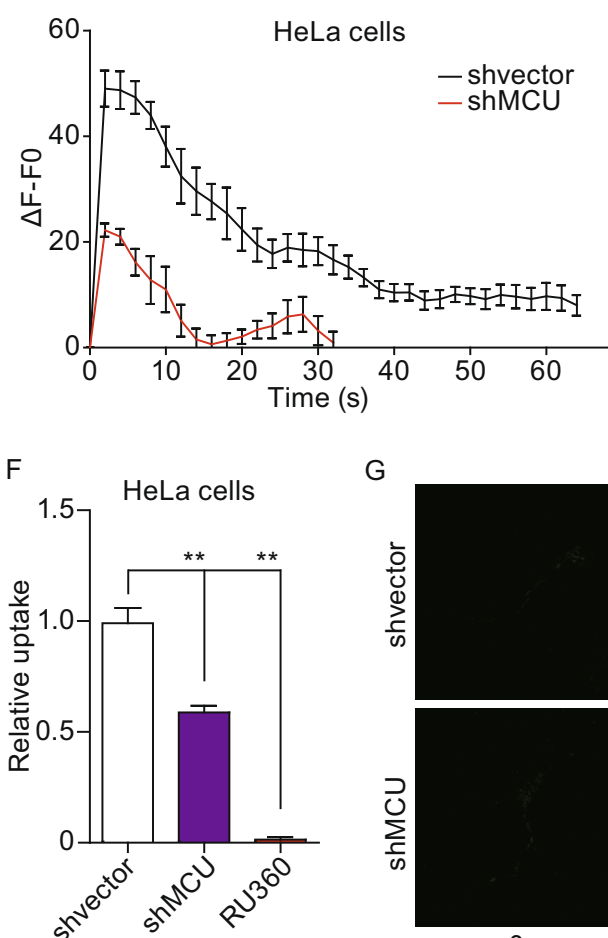

G

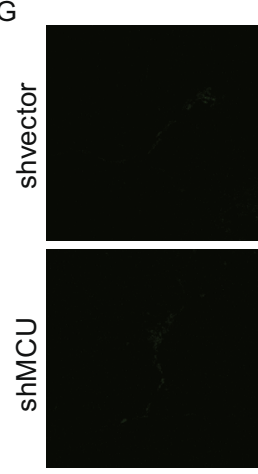

$0 \mathrm{~s}$
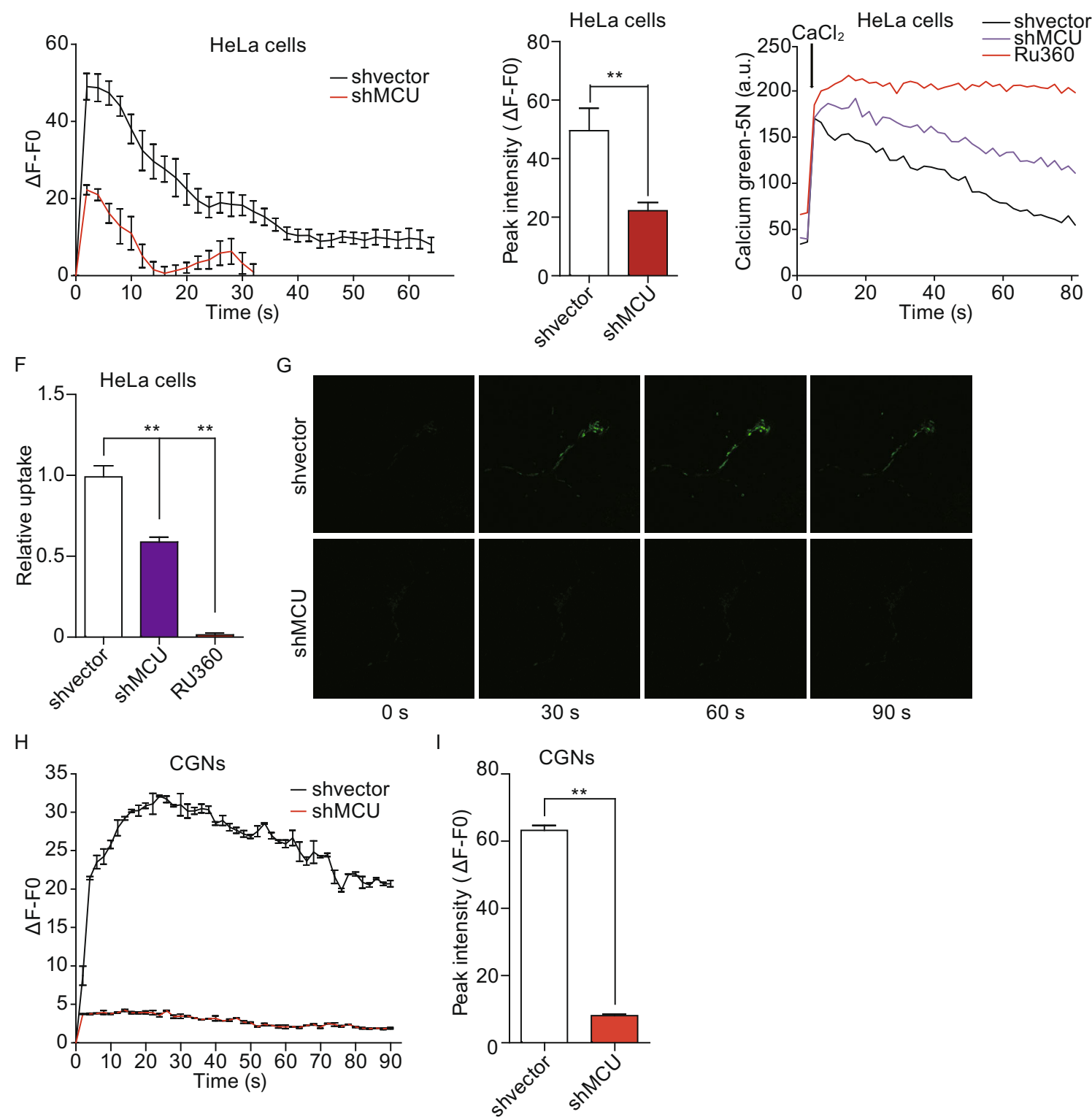
the effect of MCU knockdown on mitochondrial $\mathrm{Ca}^{2+}$ uptake was examined in digitonin-permeabilized cells. In normal condition, mitochondria could rapidly clear most of externally added $50 \mu \mathrm{mol} / \mathrm{L} \mathrm{Ca}^{2+}$. However, MCU knockdown remarkably inhibited external $\mathrm{Ca}^{2+}$ clearance, similar to Ru360, a specific MCU blocker (Fig. 2E and 2F). Consistently, in CGN cells transfected with Mito-GCaMP3, MCU knockdown dramatically blocked mitochondrial $\mathrm{Ca}^{2+}$ uptake (Fig. 2G-I). Together, these findings implicate MCU functions as a mitochondrial $\mathrm{Ca}^{2+}$ uniporter in both HeLa cells and CGNs.

\section{MCU is involved in oxidative stress-induced cell death}

Next, we studied the role of MCU in oxidative induced-cell death. As shown in Fig. $3 \mathrm{~A}$ and $3 \mathrm{~B}, \mathrm{MCU}$ knockdown decreased hydrogen peroxide $\left(\mathrm{H}_{2} \mathrm{O}_{2}\right)$-induced apoptosis. Caspase- 3 activation was also reduced in MCU knockdown cells (Fig. $3 \mathrm{C}$ and $3 \mathrm{D}$ ). Accordingly, MCU overexpression significantly increased apoptosis in HeLa cells treated with $\mathrm{H}_{2} \mathrm{O}_{2}$ (Fig. 3E). We also found that MCU knockdown decreased the $\mathrm{H}_{2} \mathrm{O}_{2}$-induced cell death in CGNs as shown in Fig. $3 \mathrm{~F}$ and $3 \mathrm{G}$. Taken together, these results suggested that MCU is involved in oxidative stress-induced cell death.

MCU $\mathrm{Ca}^{2+}$ uptake activity is required for oxidative stress-induced cell death

It has been reported that $\mathrm{D} 260$ and E263 of MCU are critical for the regulation of $\mathrm{Ca}^{2+}$ uptake (Fig. 4A) and the mutations of $\mathrm{MCU}_{\mathrm{D} 260 \mathrm{~A}}$ and $\mathrm{MCU}_{\mathrm{E} 263 \mathrm{~A}}$ lose the $\mathrm{Ca}^{2+}$ uptake activity (Baughman et al., 2011). To further confirm whether the function of $\mathrm{Ca}^{2+}$ uptake activity of MCU was required for oxidative stress-induced cell death, we constructed the MCU mutants and transfected into cells. We observed that overexpression of wild type $\mathrm{MCU}$ significantly increased cell death induced by $\mathrm{H}_{2} \mathrm{O}_{2}$. However, expression of $\mathrm{MCU}_{\mathrm{D} 260 \mathrm{~A}}$ mutant or $\mathrm{MCU}_{\mathrm{E} 263 \mathrm{~A}}$ mutant failed to exaggerate oxidative stress-induced apoptosis (Fig. 4B). In addition, we found that overexpression of wild type MCU, not the mutants, increased caspase-3 cleavage (Fig. 4C and 4D). Consistently, we also found that $\mathrm{MCU}$ overexpression increased cell death induced by $\mathrm{H}_{2} \mathrm{O}_{2}$ in primary cultured CGNs, and the mutants of $M C U_{D 260 A}$ and $M C U_{E 263 A}$ had no effect on the apoptosis (Fig. 4E). Thus, these observations indicated that the $\mathrm{Ca}^{2+}$ uptake activity of MCU is required for oxidative stress-induced cell death.

MCU interacts with VDAC1 and functions as a downstream of VDAC1 during oxidative stressinduced cell death

It has been shown that VDAC1 overexpression made cells sensitive to oxidative stress (Rapizzi et al., 2002). Since both VDAC1 and MCU are involved in mitochondrial calcium uptake, we then ask whether there is functional interaction between two proteins. We firstly observed there is a physical interaction of MCU and VDAC1 (Fig. 5A). Next, we investigated the biological function of MCU-VDAC1 interaction in cells. We found that overexpression of VDAC1 increased the apoptosis induced by $\mathrm{H}_{2} \mathrm{O}_{2}$ in HeLa cells and MCU knockdown significantly inhibited VDAC1 overexpression-induced cell death, which suggests MCU functions as the downstream of VDAC1 during oxidative stress-induced apoptosis (Fig. 5B and 5C). VDAC1 has also been shown to be involved in neuronal cell death (Fernandez-Echevarria et al., 2014). Here, we found that overexpression of VDAC1 increased oxidative stress-induced apoptosis in CGNs and knockdown of MCU significantly mitigated VDAC1 overexpression-induced cell death (Fig. 5D). Taken together, these results suggested MCU functions as the downstream of VDAC1 during oxidative stress-induced cell death.

\section{DISCUSSION}

In this study, we demonstrate the role of MCU in oxidative stress-induced cell death by loss- and gain-of-function experiments. We found MCU interacts with VDAC1 and functions as the downstream in the process of oxidative stressinduced cell death.

Oxidative stress is contributed to the pathogenesis of neurological diseases, such as stroke and degenerative diseases. Mitochondrial calcium overload plays an important role in the oxidative stress-induced neuronal death. In our study, we found MCU is localized at mitochondria and functioned as a crucially $\mathrm{Ca}^{2+}$ channel in both HeLa and primary CGNs. MCU knockdown significantly blocked the mitochondrial $\mathrm{Ca}^{2+}$ uptake activity. Moreover, our functional studies indicate MCU is involved in oxidative stress-induced cell death. Recently, Pan et al. generated $\mathrm{MCU}^{-/-}$mice and found that $\mathrm{MCU}^{--}$mice are grossly normal (Pan et al., 2013), but a significant reduction of mitochondrial matrix calcium. In this study, we found that MCU knockdown did not affect the cell growth in both HeLa and primary CGNs, but rendered the cells resistant to oxidative stress. Mitochondrial $\mathrm{Ca}^{2+}$ overload is usually observed during ischemia/reperfusion $(\mathrm{I} / \mathrm{R})$, and it is considered to aggravate $\mathrm{I} / \mathrm{R}$ injury. As MCU is a mitochondrial $\mathrm{Ca}^{2+}$ uniporter, inhibition of $\mathrm{MCU}$ activity might be a therapy strategy for oxidative stress-induced diseases. For example, inhibition of MCU activity has been demonstrated to attenuate $\mathrm{I} / \mathrm{R}$ injury in multiple organs including brain, heart and liver (Dong et al., 2014; Schwartz et al., 2013; Zhao et al., 2013). Inhibition of MCU activity also protects brain and heart from iron overload-induced dysfunction (Kumfu et al., 2012; Sripetchwandee et al., 2013a; Sripetchwandee et al., 2014; Sripetchwandee et al., 2013b). Accordingly, enhancement of MCU activity increases $\mathrm{Ca}^{2+}$ level in mitochondria and promotes oxidative stress-induced apoptosis (De Stefani et al., 2011). Interestingly, recent studies showed that the role of MCU in apoptosis is dependent on cell type. Knockdown of MCU protect HeLa cells, not in MEF cells, against oxidative stress induced apoptosis 
A
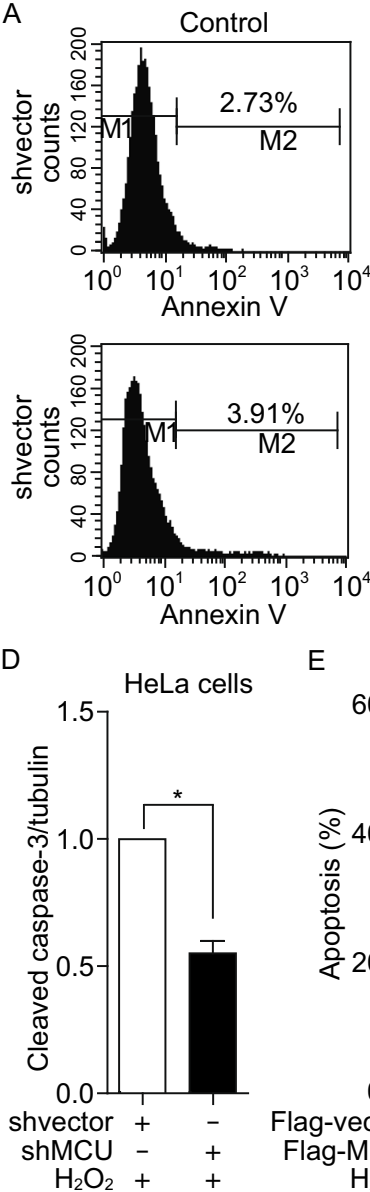

\section{E}
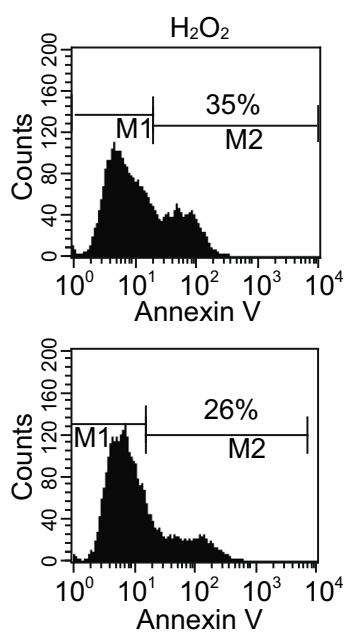

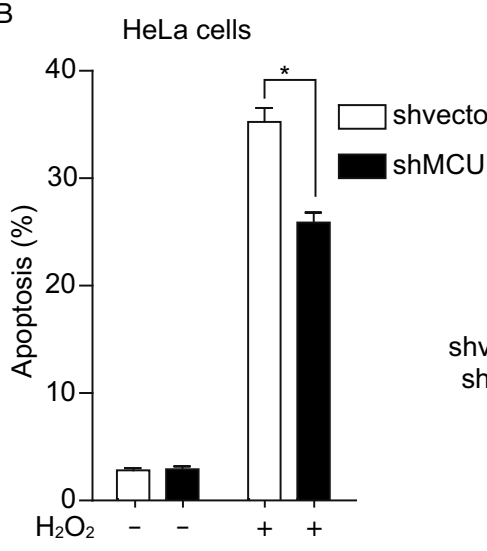

C
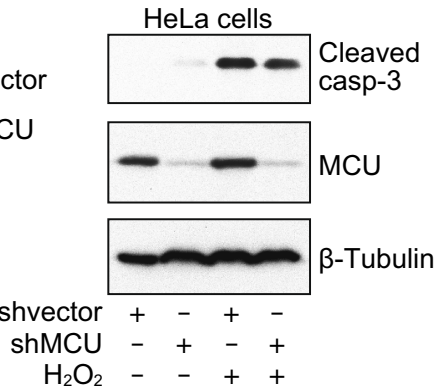

$\mathrm{H}_{2} \mathrm{O}_{2}--++$
$\mathrm{F}$

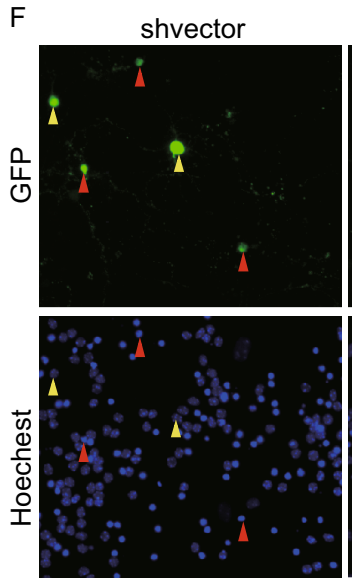

shMCU

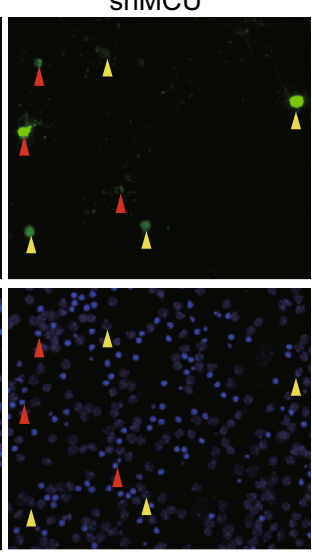

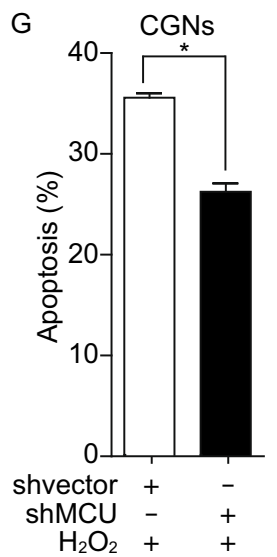

Figure 3. $\mathrm{MCU}$ is involved in oxidative stress-induced cell death. (A and $\mathrm{B}$ ) MCU silenced HeLa cells or control cells were treated with $\mathrm{H}_{2} \mathrm{O}_{2}$ for $24 \mathrm{~h}$, then, cells were collected and stained with FITC labeled annexin- $\mathrm{V}$ and finally analysis by flow cytometer. (C) MCU silenced HeLa cells or control cells were treated with $\mathrm{H}_{2} \mathrm{O}_{2}$ for $24 \mathrm{~h}$, and cells were collected and the cleaved caspase-3 was detected. (D) Graph shows normalized level of cleaved caspase-3. (E) HeLa cells tranfected with Flag-vector or Flag-MCU were exposed to $\mathrm{H}_{2} \mathrm{O}_{2}$ for $24 \mathrm{~h}$ and apoptosis was analyzed by FACS. ( $\mathrm{F}$ and G) CGNs transfected with GFP vector together with shMCU or shvector were treated with $70 \mu \mathrm{mol} / \mathrm{L} \mathrm{H}_{2} \mathrm{O}_{2}$ for $24 \mathrm{~h}$. Green arrowhead stands for the healthy cells and red arrowhead indicates apoptotic cells.

(De Stefani et al., 2011; Hall et al., 2014; Pan et al., 2013). In this study, we found that MCU knockdown attenuates oxidative stress-induced apoptosis in both HeLa and primary CGNs.

PTP is regarded as the gatekeeper of apoptosis, and its opening is regulated by several proteins, such as VDAC1, adenosine nucleotide translocase (ANT) and cyclophilin D (Halestrap et al., 1997; Pestana et al., 2010). Overexpression of these proteins makes cells sensitive to apoptoticinducing stimulus. Overexpressed VDAC1 in HeLa cells enhances cell death upon treatment with $\mathrm{H}_{2} \mathrm{O}_{2}$, staurosporine (STS), TG or $\mathrm{As}_{2} \mathrm{O}_{3}$ (Keinan et al., 2013). In this study, we found MCU knockdown remarkably inhibited VDAC1 overexpression induced-cell death, suggesting MCU functions as a downstream of VDAC1 during oxidative stress-induced cell death.
In summary, we showed that VDAC1 (outer member) and MCU (inner member) form complex and mediate mitochondrial calcium uptake and stress-induced cell death. Furthermore, we showed that MCU is involved in oxidative stressinduced apoptosis as a downstream regulator of VDAC1. Therefore, the inhibition of the activity of MCU or disruption of VDAC1-MCU interaction might be a strategy to stroke and degenerative diseases.

\section{MATERIALS AND METHODS}

\section{Materials}

$\mathrm{H}_{2} \mathrm{O}_{2}$, anti-Flag $\mathrm{M} 2 \mathrm{mAb}$ and Anti-MCU pAb were purchased from Sigma-Aldrich. Anti-active caspase-3 $p A b$ was purchased from Millipore. Anti-GFP pAb, anti-GAPDH mAb, anti- $\beta$-tubulin mAb were 


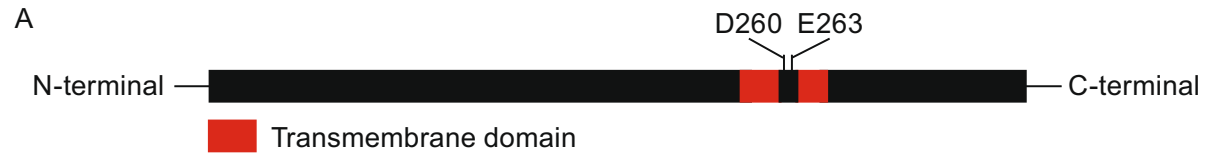

B

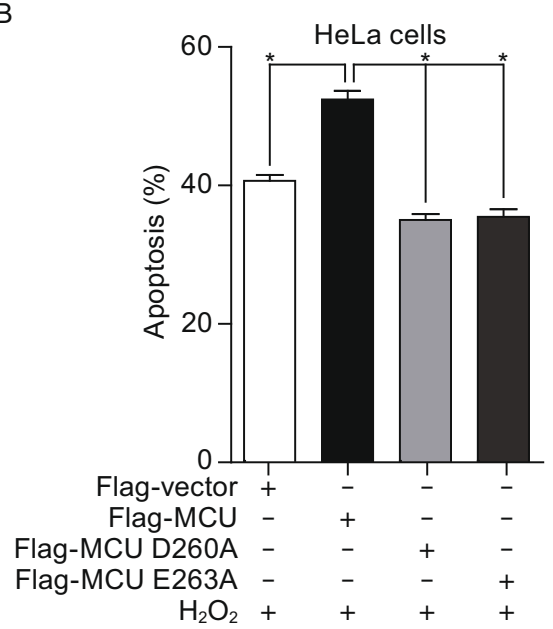

D

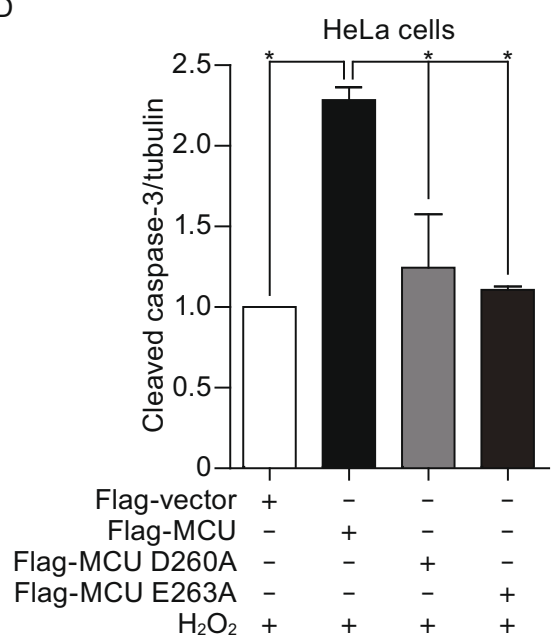

C

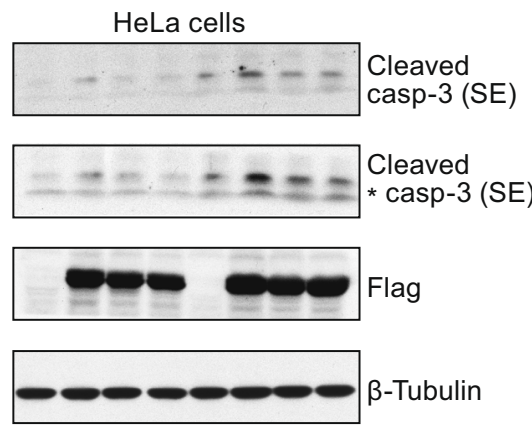

Flag-vector +--++-

Flag-MCU -+---+-

Flag-MCU D260A - - + - - + -

Flag-MCU E263A - - - + - - +

$\mathrm{H}_{2} \mathrm{O}_{2}---+++$

E

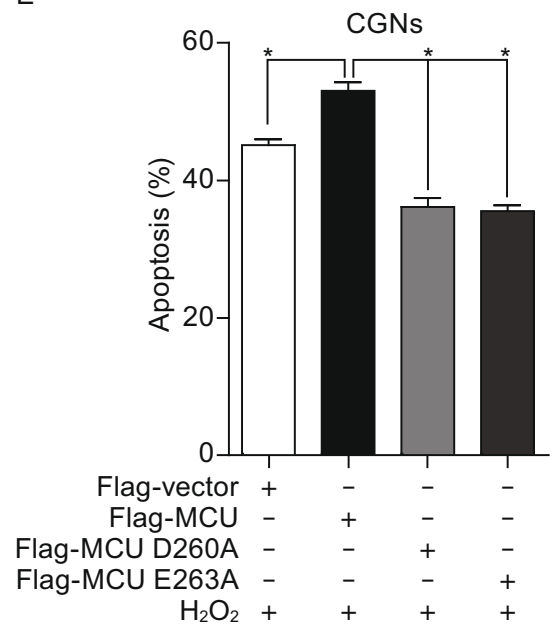

Figure 4. The calcium uptake activity of $M C U$ is required for oxidative stress-induced cell death. (A) The critical site for calcium uptake activity of MCU. (B) HeLa cells were overexpressed with wild type $\mathrm{MCU}, \mathrm{MCU}_{\mathrm{D} 260 \mathrm{~A}}$ or $\mathrm{MCU}_{\mathrm{E} 263 \mathrm{~A}}$, and then cells were treated with $\mathrm{H}_{2} \mathrm{O}_{2}$ for $24 \mathrm{~h}$. The apoptosis was finally analyzed by FACS. (C) HeLa cells transfected with wild type MCU, MCU $\mathrm{D}_{260 \mathrm{~A}}$ or $\mathrm{MCU}_{\mathrm{E} 263 \mathrm{~A}}$ as indicated were treated with $200 \mu \mathrm{mol} / \mathrm{L} \mathrm{H}_{2} \mathrm{O}_{2}$ for $24 \mathrm{~h}$. Cleaved caspase-3 were analyzed (“*” means non-specific band). (D) Graph shows normalized level of cleaved caspase-3. (E) CGNs transfected with GFP vector plus wild type MCU, MCU $\mathrm{D}_{260 \mathrm{~A}}$ mutant, $\mathrm{MCU}_{\mathrm{E} 263 \mathrm{~A}}$ mutant or empty vector were treated with $70 \mu \mathrm{mol} / \mathrm{L} \mathrm{H}_{2} \mathrm{O}_{2}$ for $24 \mathrm{~h}$.

purchased from CWbiotech. Primers for shRNA were synthesized by Invitrogen and cloned into pLKO.1 vector.

Cell culture and transfection

HeLa cells were maintained in DMEM supplied with $10 \%$ fetal bovine serum at $37^{\circ} \mathrm{C}$ in a humidified atmosphere with $5 \% \mathrm{CO}_{2}$. Mouse primary cerebellar granule neurons (CGNs) were isolated from 10 days old mouse as previously described (Xie et al., 2012). Isolated CGNs were cultured in BME supplemented with $10 \mu \mathrm{mol} / \mathrm{L}$ cytosine arabinoside (AraC) and $25 \mathrm{mmol} / \mathrm{L}$ glucose. Lipofectamine 2000 reagent was applied for transfection in HeLa cells according to the manufacturer's instructions. For transfection of CGNs, the classical calcium phosphate coprecipitation technique was used.

Imaging of mitochondrial calcium

Mitochondrial $\mathrm{Ca}^{2+}$ uptake in intact cells was detected as previously described (Qiu et al., 2013). Briefly, cells plated on 35-mm glassbottom dishes were transfected with Mito-GCaMP3 to monitor the concentration of $\mathrm{Ca}^{2+}$ in mitochondrial. $24 \mathrm{~h}$ post transfection, timelapse confocal microscopy was started at $1-\mathrm{sec}$ intervals using a 


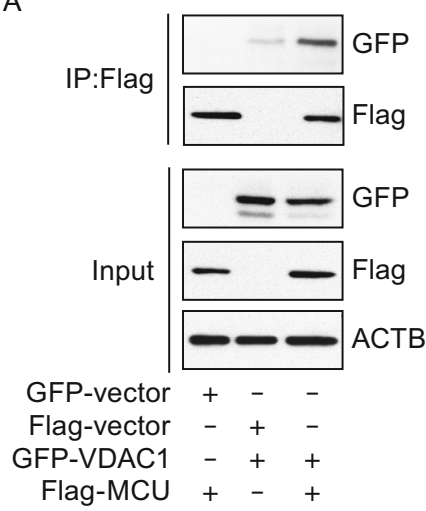

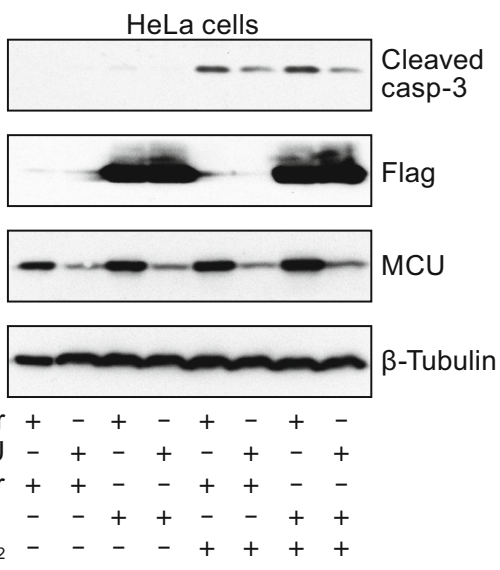

C

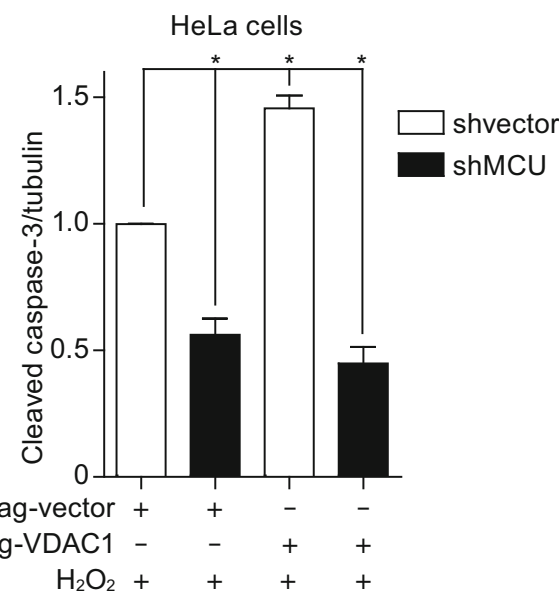

D

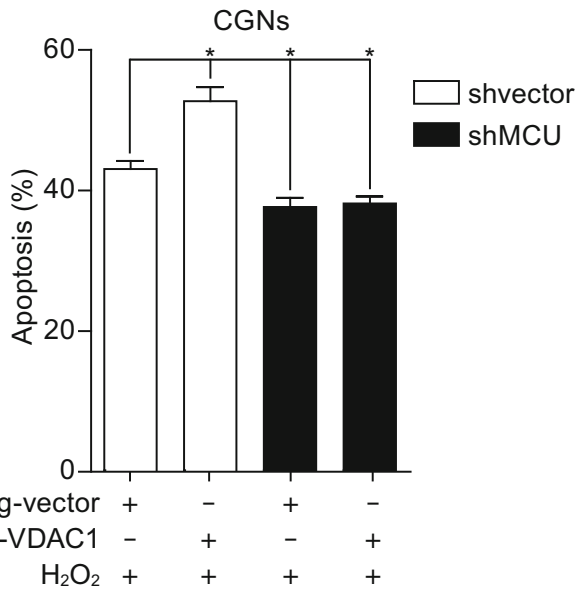

Figure 5. MCU interacts with VDAC1 and functions as a downstream of VDAC1. (A) Flag-MCU was transfected into cells together with GFP-VDAC1 or empty vector. Twenty-four hours later, cells were collected and immunoprecipitated using anti-Flag M2 beads. (B) Normal or MCU knockdown HeLa cells were transfected with Flag-VDAC1 or empty vector. Twenty-four hours later, cells were treated with $200 \mu \mathrm{mol} / \mathrm{L} \mathrm{H}_{2} \mathrm{O}_{2}$ for another $24 \mathrm{~h}$ and cleaved caspase-3 was analyzed. (C) Graph shows normalized level of cleaved caspase-3. (D) CGNs transfected with shMCU or shvector, Flag-VDAC1 or empty vector as indicated were treated with $70 \mu \mathrm{mol} / \mathrm{L} \mathrm{H}_{2} \mathrm{O}_{2}$ for $24 \mathrm{~h}$.

$40 \times$ objective lens. Images were obtained using laser scanning confocal microscope. GCaMP3 was excited using the $488 \mathrm{~nm}$ line of an argon laser and detected at $530-550 \mathrm{~nm}$. Ten to fifteen cells were randomly selected in each scan by drawing regions around individual cells, and the green fluorescence intensity was monitored sequentially. The results are representative of at least three independent experiments, and we have confirmed the reproducibility of these findings.

Calcium uptake in permeabilized HeLa cells

Mitochondrial $\mathrm{Ca}^{2+}$ uptake in permeabilized cells was tested as previously described (Sancak et al., 2013). Briefly, HeLa cells grown in $10 \mathrm{~cm}$ tissue culture plates were trypsinized and resuspended in $10 \mathrm{~mL}$ of DMEM. One million of each cell lines were transferred to microcentrifuge tubes, followed by spining down for $3 \mathrm{~min}$ at $800 \times g$ at room temperature. Then cells were washed with $\mathrm{PBS}$ once and resuspended in $\mathrm{KCl}$ buffer $\left(125 \mathrm{mmol} / \mathrm{L} \mathrm{KCl}, 2 \mathrm{mmol} / \mathrm{L} \mathrm{K}_{2} \mathrm{HPO}_{4}\right.$,
$1 \mathrm{mmol} / \mathrm{L} \mathrm{MgCl} 2,20 \mathrm{mmol} / \mathrm{L}$ HEPES, $\mathrm{pH}$ 7.2), supplemented with $5 \mathrm{mmol} / \mathrm{L}$ glutamate and malate, $0.01 \%$ digitonin and $0.8 \mu \mathrm{mol} / \mathrm{L}$ Green-5N. Fluorescence was monitored every $0.2 \mathrm{~s}$ before and after addition of $50 \mu \mathrm{mol} / \mathrm{L}$ final concentration of $\mathrm{Ca}^{2+}$ at $27^{\circ} \mathrm{C}$ using a Thermo Scientific Varioskan Flash, filter sets (Ex506/Em532).

\section{Immunoblot analysis}

Cells were lysed in RIPA buffer (strong) (biyuntian, China). The concentration of total proteins was determined using BCA protein concentration detection kit (biyuntian, China). The same amount of proteins were loaded on SDS-PAGE and resolved by electrophoresis, followed by transferring onto NC membrane. Then, the membranes were blocked with blocking buffer (5\% fat-free dry milk in TBST buffer) and incubated with primary antibodies and HRP labeled secondary antibodies, respectively. Lastly, specific proteins were visualized with enhanced ECL plus Western blotting substrate according the manufacturer's instructions (Thermo). 


\section{Apoptosis analysis}

For HeLa cells, apoptotic cells were quantified by flow cytometry using an Annexin-V-FITC apoptosis detection kit (biyuntian) following the manufacturer's instructions. For CGNs, apoptotic cells were detected by nuclei staining using Hoechest 33342. Primary CGNs were isolated and seeded on glass piece. Seven days later, cells were transfected with plasmid or shRNA. Forty-eight hours later, cells were treated with $70 \mu \mathrm{mol} / \mathrm{L} \mathrm{H}_{2} \mathrm{O}_{2}$ for $24 \mathrm{~h}$, and then cells were fixed and stained with Hoechest 33342. Neuronal apoptosis assay was performed as described (Konishi and Bonni, 2003) by using the Zeiss imager D1 microscope.

\section{Statistical analysis of data}

Statistical data are presented as mean \pm S.D. Significance was calculated by Student's $t$-test ( ${ }^{*}$ means $P<0.05$, ${ }^{* *}$ means $P<0.01$ ).

\section{ACKNOWLEDGEMENTS}

This work was supported by a grant from Beijing Nature Science Foundation (Grant No. 7132147). We sincerely thank Professor Guangju Ji for kindly providing plasmid Mito-GCaMP3 for us.

\section{ABBREVIATIONS}

MCU, mitochondrial calcium uniporter; CGN, cerebellar granule neurons; VDAC, voltage-dependent anion-selective channel protein.

\section{COMPLIANCE WITH ETHICS GUIDELINES}

Yajin Liao, Yumin Hao, Hong Chen, Qing He, Zengqiang Yuan and Jinbo Cheng declare that they have no conflict of interest. All institutional and national guidelines for the care and use of laboratory animals were followed.

\section{OPEN ACCESS}

This article is distributed under the terms of the Creative Commons Attribution License which permits any use, distribution, and reproduction in any medium, provided the original author(s) and the source are credited.

\section{REFERENCES}

Ahuja M, Muallem S (2014) The gatekeepers of mitochondrial calcium influx: MICU1 and MICU2. EMBO Rep 15:205-206

Alam MR, Groschner LN, Parichatikanond W, Kuo L, Bondarenko Al, Rost R, Waldeck-Weiermair M, Malli R, Graier WF (2012) Mitochondrial $\mathrm{Ca}^{2+}$ uptake 1 (MICU1) and mitochondrial $\mathrm{Ca}^{2+}$ uniporter (MCU) contribute to metabolism-secretion coupling in clonal pancreatic beta-cells. J Biol Chem 287:34445-34454

Baughman JM, Perocchi F, Girgis HS, Plovanich M, Belcher-Timme CA, Sancak Y, Bao XR, Strittmatter L, Goldberger O, Bogorad RL, Koteliansky V, Mootha VK (2011) Integrative genomics identifies MCU as an essential component of the mitochondrial calcium uniporter. Nature 476:341-345

Ben-Hail D, Shoshan-Barmatz V (2012) Anion-transport blockers inhibit VDAC1 channel conductance, oligomerization and apoptosis. Febs J 279:429-429
Brustovetsky N, Brustovetsky T, Jemmerson R, Dubinsky JM (2002) Calcium-induced cytochrome $c$ release from CNS mitochondria is associated with the permeability transition and rupture of the outer membrane. J Neurochem 80:207-218

Chu ZL, Pio F, Xie Z, Welsh K, Krajewska M, Krajewski S, Godzik A, Reed JC (2001) A novel enhancer of the Apaf1 apoptosome involved in cytochrome c-dependent caspase activation and apoptosis. J Biol Chem 276:9239-9245

De Stefani D, Raffaello A, Teardo E, Szabo I, Rizzuto R (2011) A forty-kilodalton protein of the inner membrane is the mitochondrial calcium uniporter. Nature 476:336-340

Dong HL, Wang SL, Zhang ZW, Yu AL, Liu Z (2014) The effect of mitochondrial calcium uniporter opener spermine on diazoxide against focal cerebral ischemia-reperfusion injury in rats. J Stroke Cerebrovasc 23:303-309

Fernandez-Echevarria C, Diaz M, Ferrer I, Canerina-Amaro A, Marin $R$ (2014) Abeta promotes VDAC1 channel dephosphorylation in neuronal lipid rafts. Relevance to the mechanisms of neurotoxicity in Alzheimer's disease. Neuroscience 278:354-366

Gincel D, Zaid H, Shoshan-Barmatz V (2001) Calcium binding and translocation by the voltage-dependent anion channel: a possible regulatory mechanism in mitochondrial function. Biochem $\mathrm{J}$ 358:147-155

Halestrap AP, Connern CP, Griffiths EJ, Kerr PM (1997) Cyclosporin A binding to mitochondrial cyclophilin inhibits the permeability transition pore and protects hearts from ischaemia/reperfusion injury. Mol Cell Biochem 174:167-172

Hall DD, Wu YJ, Domann FE, Spitz DR, Anderson ME (2014) Mitochondrial calcium uniporter activity is dispensable for MDAMB-231 breast carcinoma cell survival. PLoS ONE 9:e96866

Keinan N, Pahima H, Ben-Hail D, Shoshan-Barmatz V (2013) The role of calcium in VDAC1 oligomerization and mitochondriamediated apoptosis. Bba-Mol Cell Res 1833:1745-1754

Kinnally KW, Peixoto PM, Ryu SY, Dejean LM (2011) Is mPTP the gatekeeper for necrosis, apoptosis, or both? Biochimica et biophysica acta 1813:616-622

Konishi Y, Bonni A (2003) The E2F-Cdc2 cell-cycle pathway specifically mediates activity deprivation-induced apoptosis of postmitotic neurons. J Neurosci 23:1649-1658

Kumfu S, Chattipakorn S, Fucharoen S, Chattipakorn N (2012) Mitochondrial calcium uniporter blocker prevents cardiac mitochondrial dysfunction induced by iron overload in thalassemic mice. Biometals 25:1167-1175

Madesh M, Hajnoczky G (2001) VDAC-dependent permeabilization of the outer mitochondrial membrane by superoxide induces rapid and massive cytochrome $c$ release. J Cell Biol 155:10031015

Mallilankaraman K, Cardenas C, Doonan PJ, Chandramoorthy HC, Irrinki KM, Golenar T, Csordas G, Madireddi P, Yang J, Muller M, Miller R, Kolesar JE, Molgo J, Kaufman B, Hajnoczky G, Foskett JK, Madesh M (2012a) MCUR1 is an essential component of mitochondrial $\mathrm{Ca}^{2+}$ uptake that regulates cellular metabolism. Nature Cell Biol 14:1336-1343

Mallilankaraman K, Doonan P, Cardenas C, Chandramoorthy HC, Muller M, Miller R, Hoffman NE, Gandhirajan RK, Molgo J, Birnbaum MJ, Rothberg BS, Mak DO, Foskett JK, Madesh M (2012b) MICU1 is an essential gatekeeper for MCU-mediated 
mitochondrial $\mathrm{Ca}(2+)$ uptake that regulates cell survival. Cell 151:630-644

Naranmandura H, Chen X, Tanaka M, Wang WW, Rehman K, Xu S, Chen Z, Chen SQ, Suzuki N (2012) Release of apoptotic cytochrome $\mathrm{C}$ from mitochondria by dimethylarsinous acid occurs through interaction with voltage-dependent anion channel in vitro. Toxicol Sci 128:137-146

Pan X, Liu J, Nguyen T, Liu CY, Sun JH, Teng YJ, Fergusson MM, Rovira II, Allen M, Springer DA, Aponte AM, Gucek M, Balaban RS, Murphy E, Finkel T (2013) The physiological role of mitochondrial calcium revealed by mice lacking the mitochondrial calcium uniporter. Nature Cell Biol 15:1464-1472

Pestana CR, Silva CH, Uyemura SA, Santos AC, Curti C (2010) Impact of adenosine nucleotide translocase (ANT) proline isomerization on $\mathrm{Ca}^{2+}$-induced cysteine relative mobility/mitochondrial permeability transition pore. J Bioenerg Biomembr 42:329-335

Qiu J, Tan YW, Hagenston AM, Martel MA, Kneisel N, Skehel PA, Wyllie DJ, Bading H, Hardingham GE (2013) Mitochondrial calcium uniporter MCU controls excitotoxicity and is transcriptionally repressed by neuroprotective nuclear calcium signals. Nat Commun 4:2034

Raffaello A, De Stefani D, Sabbadin D, Teardo E, Merli G, Picard A, Checchetto V, Moro S, Szabo I, Rizzuto R (2013) The mitochondrial calcium uniporter is a multimer that can include a dominantnegative pore-forming subunit. EMBO J 32:2362-2376

Rapizzi E, Pinton P, Szabadkai G, Wieckowski MR, Vandecasteele G, Baird G, Tuft RA, Fogarty KE, Rizzuto R (2002) Recombinant expression of the voltage-dependent anion channel enhances the transfer of $\mathrm{Ca} 2+$ microdomains to mitochondria. J Cell Biol 159:613-624

Robb-Gaspers LD, Burnett P, Rutter GA, Denton RM, Rizzuto R, Thomas AP (1998) Integrating cytosolic calcium signals into mitochondrial metabolic responses. Embo J 17:4987-5000

Sancak Y, Markhard AL, Kitami T, Kovacs-Bogdan E, Kamer KJ, Udeshi ND, Carr SA, Chaudhuri D, Clapham DE, Li AA, Calvo SE, Goldberger O, Mootha VK (2013) EMRE is an essential component of the mitochondrial calcium uniporter complex. Science 342:1379-1382

Schwartz J, Holmuhamedov E, Zhang X, Lovelace GL, Smith CD, Lemasters JJ (2013) Minocycline and doxycycline, but not other tetracycline-derived compounds, protect liver cells from chemical hypoxia and ischemia/reperfusion injury by inhibition of the mitochondrial calcium uniporter. Toxicol Appl Pharmacol 273:172-179

Shoshan-Barmatz V, Zakar M, Rosenthal K, Abu-Hamad S (2009) Key regions of VDAC1 functioning in apoptosis induction and regulation by hexokinase. Biochimica et biophysica acta 1787:421-430

Shoshan-Barmatz V, Keinan N, Abu-Hamad S, Tyomkin D, Aram L (2010) Apoptosis is regulated by the VDAC1 N-terminal region and by VDAC oligomerization: release of cytochrome $c$, AIF and Smac/Diablo. Bba-Bioenergetics 1797:1281-1291

Sripetchwandee J, Kenknight S, Sanit J, Chattipakorn S, Chattipakorn N (2013a) Blocking mitochondrial calcium uniporter completely prevents cardiac mitochondrial dysfunction caused by iron overload. J Am Coll Cardiol 61:E705-E705

Sripetchwandee J, Sanit J, Chattipakorn N, Chattipakorn SC (2013b) Mitochondrial calcium uniporter blocker effectively prevents brain mitochondrial dysfunction caused by iron overload. Life Sci 92:298-304

Sripetchwandee J, KenKnight SB, Sanit J, Chattipakorn S, Chattipakorn N (2014) Blockade of mitochondrial calcium uniporter prevents cardiac mitochondrial dysfunction caused by iron overload. Acta Physiol 210:330-341

Xie Q, Hao Y, Tao L, Peng S, Rao C, Chen H, You H, Dong MQ, Yuan Z (2012) Lysine methylation of FOXO3 regulates oxidative stress-induced neuronal cell death. EMBO reports 13:371-377

Xu X, Decker W, Sampson MJ, Craigen WJ, Colombini M (1999) Mouse VDAC isoforms expressed in yeast: channel properties and their roles in mitochondrial outer membrane permeability. J Membr Biol 170:89-102

Zhao Q, Wang SL, Li Y, Wang P, Li SH, Guo YL, Yao RY (2013) The role of the mitochondrial calcium uniporter in cerebral ischemia/ reperfusion injury in rats involves regulation of mitochondrial energy metabolism. Mol Med Rep 7:1073-1080

Zheng Y, Shi Y, Tian C, Jiang C, Jin H, Chen J, Almasan A, Tang H, Chen $Q$ (2004) Essential role of the voltage-dependent anion channel (VDAC) in mitochondrial permeability transition pore opening and cytochrome $c$ release induced by arsenic trioxide. Oncogene 23:1239-1247 